\title{
Prognostic Implication of Serum Magnesium Levels in Patients with Chronic Stable Asthma
}

\author{
${ }^{1}$ Dr.S.Sopnajothi $\mathrm{Md}(\mathrm{Gm}){ }^{2}$ dr.Sooriyakumar Md $(\mathrm{Gm})$ \\ ${ }^{3}$ Prof.Dr.S.Vadivelmurugan Md (Gm), ${ }^{4}$ Prof.Dr.T.Ravikumar Md (Gm), Hod , \\ ${ }^{5}$ Prof.Dr.Purusothaman $\mathrm{Md}(\mathrm{Gm})$, Hod , \\ ${ }^{1}$ Assistant Professor,Department of General Medicine, Govt Theni Medical College,Theni. \\ ${ }^{2}$ Associate Professor,Department of General medicine, Govt Theni Medical college,Theni. \\ ${ }^{3}$ Professor, Department of General Medicine, Vellammal Medical college, Madurai. \\ ${ }^{4}$ Department of General Medicine, ESI medical college, Coimbatore . \\ ${ }^{5}$ Department of general medicine, Govt Theni Medical college ,Theni.
}

\begin{abstract}
:
Background: Magnesium has been used in the treatment of acute exacerbation of asthma for a long time, but the role of hypomagnesaemia in chronic stable asthma and its prognostic implications have not been fully established.

Objectives:We conducted this study - (i)To assess the levels of serum magnesium and its prognostic implications in patients with chronic stable asthma and (ii) to find out any correlation between the severity of asthma and hypomagnesemia.

Setting: Government Rajaji hospital ,Madurai, TamilNadu.

Period of study: June 2013 to November 2013

Study Design: 100 patients with chronic stable asthma attending outpatient departments of Thoracic Medicine and General Medicine and 50 healthy controls were randomly selected. The asthmatic patients were assessed by spirometry and serum magnesium levels were determined for all. Descriptive statistics were applied to the obtained data and results were analyzed as significant if the p value was $<0.05$.

Results: 34 percent of asthmatic patients were found to have hypomagnesemia. The mean levels of magnesium was 1.55 in cases and 2.03 in controls ( $p<0.001)$.

Conclusion: There was statistically significant hypomagnesemia in patients with chronic stable asthma. Low levels of magnesium were found to correlate with severity of asthma and. There was no significant correlation of magnesium levels with age, gender or duration of asthma.
\end{abstract}

Key words: Chronic stable asthma, Magnesium, Disease severity, Spirometry.

\section{Introduction}

Asthma is a serious public health problem throughout the world, affecting people of all ages. It is estimated that around 300 million people worldwide currently have asthma. Diagnosing asthma at an earlier stage and instituting appropriate therapy decreases the socio economic burden for asthmatics and significantly enhances the quality of the patient's life, as medications continue to be the mainstay of treatment and contributes to a major chunk of the cost involved.

The total magnesium content of our body is about $25 \mathrm{gm}(1000 \mathrm{mmol}) .50 \%$ of this is present in bones and only about $1 \%$ is present in the extracellular fluid, the remaining being intracellular. Approximately $30 \%$ of serum magnesium is bound to albumin. Magnesium deficiency has been associated with a number of chronic diseases like diabetes mellitus, hypertension and dyslipidemia. Therapeutically, magnesium is found to be useful in acute coronary events, preeclampsia, eclampsia and ventricular tachyarrythmias. In the case of acute asthma both intravenous and inhaled magnesium can be used.

International guidelines recommend the use of intravenous Mgso4 in case of acute severe asthma, especially if FEV1 levels are between 25 to $30 \%$ of predicted values at presentation, or when there is poor response to short acting beta 2 agonists. The possible mechanisms of action of magnesium in bronchial asthma are inhibition of vascular and bronchial smooth muscle contraction, inhibition of release of acetylcholine from cholinergic nerves, enhancement of nitric oxide and prostaglandin generation and smooth muscle stabilization. As an intracellular cation, magnesium is involved in the regulation of bronchial smooth muscle tone, mast cell stabilization, neuromuscular activity and respiratory muscle function. Low intracellular magnesium concentration may promote the hyper responsiveness of airways in asthmatic patients.

International guidelines recommend the use of magnesium through intravenous route for treating acute severe exacerbations of asthma unresponsive to other standard medications. They have established that isotonic 
magnesium sulphate used as a vehicle for nebulised salbutamol has a good efficacy in the management of severe exacerbations of asthma.

\section{Aim Of Study}

To assess the levels of serum magnesium in patients with chronic stable asthma and to find out any correlation between the severity of asthma and hypomagnesemia.

\section{Materials And Methods}

This study was undertaken with the aim to determine serum magnesium levels in patients with chronic stable asthma and to determine whether low levels of magnesium was associated with disease severity and higher incidence of hospitalizations and to assess whether therapeutic drugs used in the management of asthma have an effect on magnesium levels.

\section{Study population:}

This study was conducted at Government Rajaji Hospital, Madurai on a total of 150 subjects of age more than 12 years who attended the outpatient department: of whom 50 were apparently healthy and served as controls.

Study design : Cross sectional analytical study

Period of study :The study duration was from June 2013 to November 2013.

Ethical Clearance : Obtained

Consent: Individual written and informed consent.

The cases were selected as follows :

\section{Inclusion criteria:}

$>$ Patients with stable asthma ( defined as no history of exacerbation at the time of presentation or within previous 1 week)

$>$ Age more than 12 years

$>$ Non smoker

\section{Exclusion criteria}

$>$ Patients with acute exacerbation of asthma

$>$ Patients with medical disorders like chronic kidney disease, diabetes mellitus, diarrhoea

$>$ Patients on diuretic therapy

$>$ Pregnancy ,breast feeding

$>$ Cardiac asthma

\section{Data collection}

For the 100 chronic asthmatic patients who were included in the study, detailed history was taken regarding symptoms, duration of asthma, previous exacerbations, seasonal variation, medications ( use of SABA, LABA, methyl xanthines,ICS, leucotriene inhibitors ), alcoholism, diabetes, cardiac illness, chronic kidney disease and diarrhea as per the proforma. It was followed by physical and respiratory system examination. Pulmonary function test using spirometry has been done. Chest $\mathrm{x}$ ray has been taken .Blood samples were collected for measurement of serum magnesium. Blood urea, serum potassium, serum albumin levels were estimated. Calorimetric method was done for the quantitative assessment of magnesium in the serum of the study and control population.

\section{Results}

Severity of Asthma was assesd based on $\mathrm{FEV}_{1} / \mathrm{FVC}$ ratio in the 100 patients with asthma .Among the cases, majority (33\%) had mild asthma while very severe disease was present only in $13 \%$.Moderate and severe degrees were almost equally distributed,29\% \& and $25 \%$ respectively .

Table 1: Comparison of Mean Serum Magnesium levels between study and control group (n=150)

\begin{tabular}{|c|c|c|c|c|c|}
\hline \multirow{2}{*}{ Statistic } & \multicolumn{2}{|c|}{ Mean } & \multirow{2}{*}{$\begin{array}{l}\text { Mean difference } \\
\text { (study-control) }\end{array}$} & \multirow{2}{*}{$\mathrm{p}$ value } & \multirow{2}{*}{$95 \%$ C.I } \\
\hline & $\begin{array}{c}\text { Study group } \\
\text { (100) }\end{array}$ & $\begin{array}{l}\text { Control group } \\
(50)\end{array}$ & & & \\
\hline Serum $\mathrm{Mg}$ & 1.557 & 2.034 & -0.477 & $<0.001$ & -0.61 to -0.343 \\
\hline
\end{tabular}




\section{Comments:}

1) The mean serum magnesium level of the study group was much lower than the mean serum magnesium level of the control group and this difference was statistically significant.

2) Hence, patients with asthma had a lower level of serum magnesium level when compared to the healthy subjects in the control group.

Table 2: Distribution of Hypomagnesaemia among study and control group $(\mathrm{n}=150)$

\begin{tabular}{|c|c|c|c|}
\hline Hypomagnesaemia & $\begin{array}{c}\text { Study group } \\
\text { N }(\%)\end{array}$ & $\begin{array}{c}\text { Control group } \\
\text { N }(\%)\end{array}$ & $\begin{array}{c}\text { Total } \\
\text { N }(\%)\end{array}$ \\
\hline Present & $34(34)$ & $2(4)$ & $36(24)$ \\
\hline Absent & $66(66)$ & $48(96)$ & $114(76)$ \\
\hline Total & $100(100)$ & $50(100)$ & $150(100)$ \\
\hline
\end{tabular}

Chi square $\mathrm{p}$ value: $<0.001$

Comments:

1) out of $36 \%$ of hypomagnesemia in total study population including control and patients, $34 \%$ of hypomagnesemia seen in the patient group and while hypomagenesemia was only $4 \%$ in the controls.

2)The difference in prevalence of hypomagnesaemia between study and control group was found to be statistically significant.

Figure 1: Distribution of hypomagnesaemia among study and control groups $(n=150)$

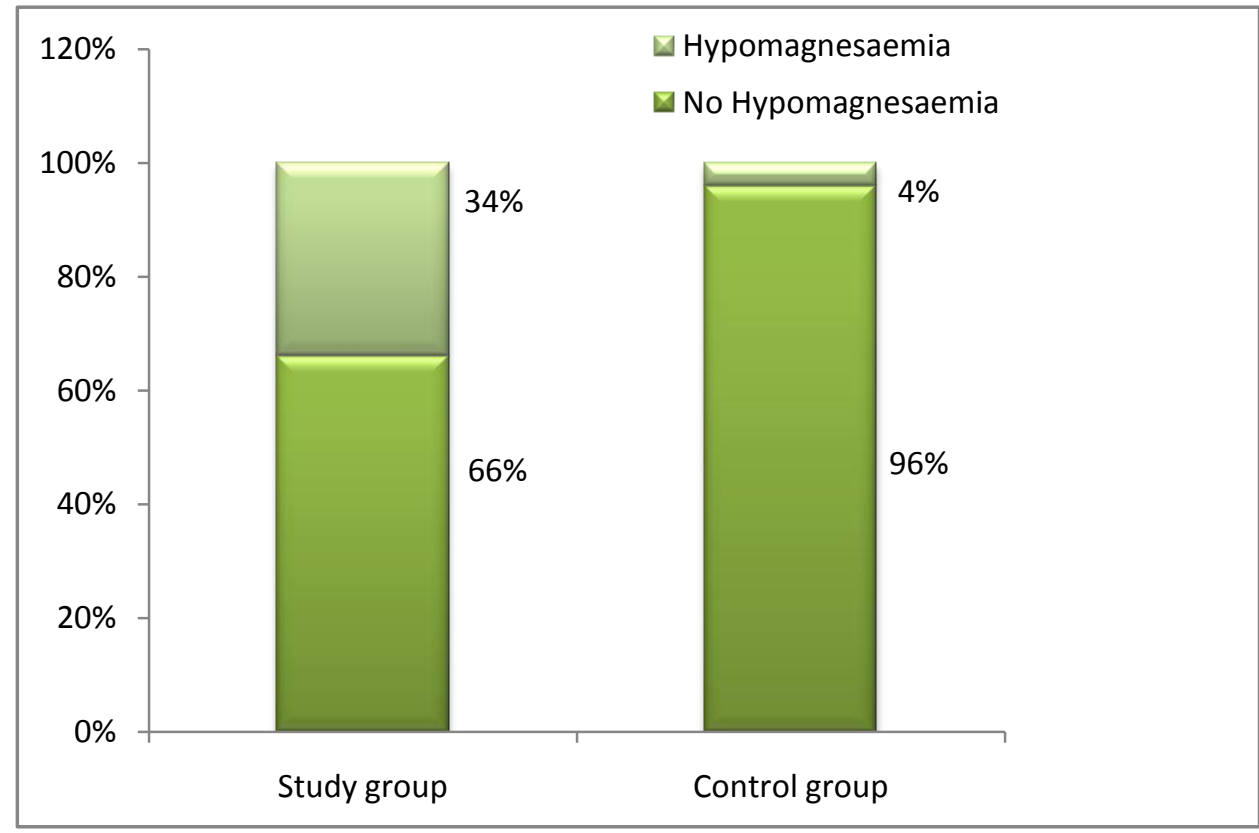

\section{Comments:}

The mean magnesium value in cases was 1.557 and in the control was 2.034 and this was significantly lower resulting from a $34 \%$ prevalence of hypomagnesemia in cases as opposed to just $4 \%$ in controls.

Table 3: Distribution of Hypomagnesaemia among study group according to Severity of Asthma ( $\mathrm{n}=100)$

\begin{tabular}{|c|c|c|c|c|c|}
\hline \multirow{2}{*}{ Hypomagnesaemia } & \multicolumn{4}{|c|}{ Severity $\mathrm{n} \%$} & Total \\
\cline { 2 - 5 } & Mild & Moderate & Severe & Very severe & \\
\hline Present & 4 & 8 & 12 & 10 & 34 \\
& $12.1 \%$ & $27.6 \%$ & $48.0 \%$ & $76.9 \%$ & $34.0 \%$ \\
\hline Absent & 29 & 21 & 13 & 3 & 66 \\
& $87.9 \%$ & $72.4 \%$ & $52.0 \%$ & $23.1 \%$ & $66.0 \%$ \\
\hline Total & 33 & 29 & 25 & 13 & 100 \\
& $100 \%$ & $100 \%$ & $100 \%$ & $100 \%$ & $100 \%$ \\
\hline
\end{tabular}

Chi-square p value: $<0.001$

The prevalence of hypomagnesaemia was increasing with increasing severity of disease and this difference across various levels of severity was statistically significant. 
Figure 2: Distribution of Hypomagnesaemia according to severity of Asthma

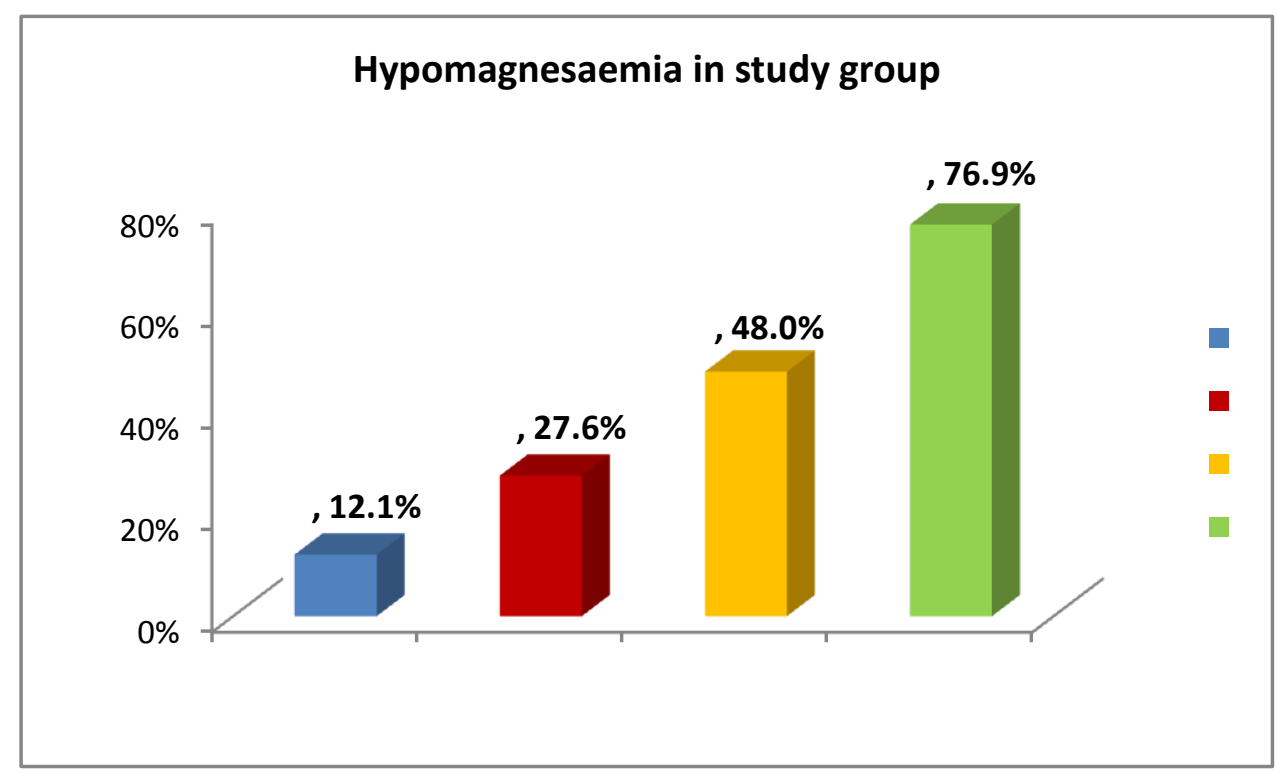

Table 4: Logistic regression model for Hypomagnesaemia among study group according to Severity of Asthma $(\mathrm{n}=100)$

\begin{tabular}{|c|c|c|c|c|}
\hline \multirow{2}{*}{ Severity } & \multirow{2}{*}{ ODDS RATIO } & \multirow{2}{*}{$\mathrm{p}$ value } & \multicolumn{2}{|c|}{ 95\% C.I.for EXP(B) } \\
\cline { 4 - 5 } & & & Lower & Upper \\
\hline Mild (referent) & 1 & - & - & - \\
\hline Moderate & 2.762 & 0.133 & 0.734 & 10.392 \\
\hline Severe & 6.692 & 0.004 & 1.811 & 24.730 \\
\hline Very severe & 24.167 & 0.000 & 4.592 & 127.171 \\
\hline
\end{tabular}

\section{Comments:}

1) When compared to subjects with mild asthma, subjects with moderate, severe and very severe asthma had higher prevalence of hypomagnesaemia (OR: 2.7, 6.6, and 24.1, respectively).

2) The higher odds ratio for subjects with severe and very severe asthma when compared to mild disease was statistically significant but it was not significant in case of moderate vs mild disease.

\section{Discussion}

A high prevalence of low plasma magnesium concentrations among patients with bronchial asthma has been reported in various studies and there is a possible association of hypomagnesemia with the severity of bronchial asthma.However, some workers have also reported normal values in asthma. Hence we have attempted to assess the presence of hypomagnesemia in chronic stable asthma patients.In our study, the prevalence of low serum magnesium concentrations in chronic stable asthma patients was $34 \%$. This conforms to the reported prevalence of hypomagnesemia in chronic stable asthmatics in several studies, which ranged from 26 to $40 \%$.

"Khosrow Agin" et alwho studied asthmatic patients attending pulmonary medicine department of Loghmann Hakim Hospital at Tehran - Iran, described 40.5\% prevalence of hypomagnesemia in patients with chronic stable asthma.The figure was $27 \%$ in the study by "O.S.B .Aloamoudi" et al., done at the Medicine department of King AbdulAziz University hospital, Jeddah in Kingdom of Saudi Arabia

\section{Conclusion}

There is presence of hypomagnesemia in chronic stable asthma and the prevalence was found to be $34 \%$. There is a significant difference in magnesium levels between patients with asthma compared to normal population. Mean magnesium in the study group was 1.557 and in controls it was 2.034 and this was statistically significant ( $\mathrm{p}$ value $<0.001$ ). It was found that hypomagnesemia has no significant correlation with age, gender or duration of asthma.. Hypomagnesemia is significantly associated with severity of asthma and is more prevalent in very severe asthma ( $\mathrm{p}$ value $<0.001$ ). Magnesium rich foods may be encouraged for asthmatic patients. The cause of hypomagnesemia in asthma and role of magnesium supplementation in asthmatics is an important field warranting further research. 


\section{Reference}

[1]. National Asthma Education and prevention programme. Expert panel report3 2007

[2]. Data from Global from initiative for Chronic Obstructive Lung Disease (GOLD) Global strategy for the diagnosis , mamagement and prevention of COPD ,Updated 2011.

[3]. Picado C Classification of severe asthma exacerbations: a proposal. Eur Respir J. 1996 Sep;9(9):1775-8

[4]. NIH and WHO guidelines .Asthma management and prevention. Global initiative for asthma - Global strategy for asthma management and prevention. GINA guidelines updated 2009.

[5]. Guidelines for evaluation of impairment or disability in patients with Asthma ; American Thoracic Society : Vol 147 . pp 1056 -61 , 1993

[6]. YY Yan ,MH Ng et al ,Review of the role if magnesium sulphate in the management of asthma patient at A\& E setting, Hong Kong Journal of emergency medicine

[7]. Whang R, Ryder KW , frequency of hypomagnesemia and hypermagnesemia . JAMA .1990;263: 3063 -4.

[8]. Sibes kumar das, Arup kumar Halder ,Indranath Ghosh et al,

[9]. Serum Magnesium and Stable Asthma : Is there a link .Lung India May 2013, IP 101 .63.134.102.

[10]. 9.Khosrow Agin ,Hamid Reza Jabar Darjani :Blood Serum Magnesium Values in Chronic Stable Asthmatic Patients : A Case Control Study. Tanaffos (2005) 4(13),27-32 ;

[11]. O.S.B.alamoudi, et al, Hypomagnesemia in chronic ,stable asthmatics : prevalance , correlation with severity and hospitalization , European Respiratory journal $2000 ; 16: 427-431$

[12]. Omer S.B.alamoudi et al, Electrolyte Disturbance in Patients with Chronic ,Stable Asthma . Chest 2001 ; 120 ; 431 -436 ,August 2001 .

[13]. A.Emelyanov, G.Fedoseev ,P.J.Barnes et al, Reduced intracellular magnesium concentrations in asthmatic patients ,European Respiratory Journal 1999;. $13: 38-40$

[14]. Knutsen R, Bohmer T, Falch $\mathrm{J}$ et al , Intravenous theophylline induced excretion of calcium, Mg and sodium in patients with recurrent asthmatic attacks. Scan J Clin Lab Invest 1994; 54: 119 \pm 125.430

[15]. Rolla G, Bucca C, Oliva A et al, Hypomagnesemia in chronic obstructive lung disease: effect of therapy. Mg Trace Elem 1990; 9 : $132 \pm 136$.

[16]. Britton J, Pavord I, Richards K, et al. Dietary Mg, lungfunction, wheezing, and airway hyperreactivity in a random adult population sample. Lancet 1994; 344: 357 362 .

[17]. Chande VT, Skoner DP et al ,Ttrial of nebulized Mg sulfate to reverse bronchospasm in asthmatic patients. Ann Emerg Med 1992; 21: $1111 \pm 1115$

[18]. Dominguez LJ, Barbagallo M, et al. Bronchial reactivity and intracellular magnesium: a possible mechanism for the bronchodilating effects of magnesium in asthma. Clin Sci (Lond)1998; 95 (2): 137- 42.

[19]. Noppen M, Vanmaele L, Impens $\mathrm{N}$ et al, Bronchodilating effect of intravenous $\mathrm{Mg}$ sulfate in acute severe bronchial asthma. Chest 1990; 97: 373 \pm 376 .

[20]. Okayama H, Aikawa T, Sasaki H, Mue S et al, Bronchodilating effect of iv Mg 4 in bronchial asthma. JAMA 1987; 257: 1076 \pm 1078 .

[21]. .Rolla G, Bucca C. Hypomagnesemia and bronchial hyperreactivity. A case report. Allergy 1989; 44 (7): $519-21$. 